\title{
Achieving Business Sustainability Via I-TOP Model
}

\author{
Rajendran Muthuveloo and Teoh Ai Ping \\ Graduate School of Business, Universiti Sains Malaysia, Penang, Malaysia
}

Received 2013-07-15, Revised 2013-08-01; Accepted 2013-08-02

\begin{abstract}
In the world of business, the competition is getting stiffer and stiffer daily. Sustainability has become an issue. In view of this the company and the organization has to be efficient in managing time, money and energy. I-TOP is a very fluid model that helps managers work towards optimizing the Return on Investment (ROI) in order for them to be the ROI champion in their respective organization or business community. This can be achieved through Technology Infinite Possibilities, Outright Environmental Scanning and People (Human Capital Development). Organizations that go through this I-TOP model would be able to form an organization that has worldwide efficiency that is critical for optimizing the ROI, where economic scale of business is one of the important factors.
\end{abstract}

Keywords: Business, Sustainability, Performance, Return on Investment, Strategy

\section{INTRODUCTION}

In the world of business, the competition is getting stiffer and stiffer daily. Sustainability has become an issue. In view of this the company and the organization has to be efficient in managing time, money and energy. Strategy is concerted effort to synergize the usage of time, money and energy to attain vision and mission, either at personal level, business level or corporate level.

Organizational sustainable performance refers to the actual goal achieved through proper strategies by organization. Organizational performance covers elements such as product quality and innovation, employees performance and relation with management.

If an organization wants to succeed in the worldwide competition for talent, the company needs the excellent skills of an attractive employer. Organizations in this era do face rigorous challenges regarding how the organization is propelling with very less resources and enhance the organizational sustainable performance. Organization quite often imitates what the other organizations are doing and they follow the same strategies to be on par. Organization should clearly understand the current situation of the market and take prompt action to enhance organizational sustainable performance.

There are three specific areas of an organization which includes: (i) financial performance; (ii) product and market performance; (iii) shareholders return. Gupta (2008) concluded that the ultimate goal of an organization is to create an internal environment that supports customer needs and expectations. There are four factors which could lead to performance which includes cost, time, robustness and scope where cost and time refers whether the changes are introduces and implemented quickly at a reasonable cost and robustness where the change implemented in a manner that produces quality results to accommodate changes in future.

Organizational culture is an important basis for the work practices of high performance and could be a source of competitive advantage if it is properly nurtured. A high performance organization reports a apparent course (mission, vision and strategy) which shall be embraced by employees of all levels. Teamwork, capability development and empowerment positively influence organizational performance. A positive workplace environment often motivates employess to contribute more positively to the Corresponding Author: Rajendran Muthuveloo, Graduate School of Business, Universiti Sains Malaysia, Penang, Malaysia 
organization. Ogbonna and Harris (2002) suggests and concluded that some organizational culture leads to organizational performance and that happens when the culture is widely shared among all employees. Prior to previous studies suggest that a strong culture has a positive influence on organizational sustainable performance. According to (Ramesh and Devadasan, 2007) manufacturers which quickly responds to leads to organizational performance. Andrey and Bourne (2011) shows the connection of appraisals with motivation and performance improvement. It shows that certain behaviours will lead to organizational sustainable performance. Therefore, optimisation of organizational sustainable performance refers to the strategies introduce by any organization to optimise its performance in terms of financial growth, employee retentions as well as product growth.

There are two popular strategic models vastly used in formulating strategies. The first model is called Industrial-Organizational Model (I/O Model). Strategies formed based on I/O Model depends very much on what is available within the industry. The determining factor will be whether the organization able to obtain Above Average Returns (AAR). The second model is called Organizational-Industrial Model (O/I Model). Strategies formed based on the O/I Model depends very much on what is available within the organization (i.e., availability of excess production capability). The determining factor will be whether the organization can utilize the excess capability to obtain Above Average Returns (AAR).

Both the models stated above target their output based on above average rate of return which is limited by the existing industry or business opportunities. As the world becomes borderless and business world becomes very open and competitive, these two models will not be able to optimize the rate of returns on investments by utilizing new ideas. In other words, it still falls within the red ocean strategy.

\subsection{I-Top Model}

I-TOP is a very fluid model that helps managers work towards optimizing the Return on Investment (ROI) in order for them to be the ROI champion in their respective organization or business community. This can be achieved through Technology Infinite Possibilities, Outright Environmental Scanning and People (Human Capital Development).

I-TOP stands for the following acronyms:

- I-Return on Investment

- T-Technology Infinite Possibilities
- O-Outright Environmental Scanning

- P-People (Human Capital Development)

This model is built based on the author's 20 years of experience in business particularly business development and continuous research work. The philosophy behind this model is optimizing return on investment via Technology Infinite Possibilities, Outright Environmental Scanning and People (Human Capital Development).

The model propagates the message of BOSS via ITOP, which means that the organization can only be the leader/top, by optimizing the Return on Investment. In other words, one (I) only can be top or successful if one (I) could optimize the ROI. This is a very fluid model which utilizes Technology Infinite Possibilities (e.g., blue ocean strategy, disruptive innovation, business innovation), Outright Environmental Scanning (e.g., global scenario planning and organizational type/structure) and People (Human Capital Development). I-TOP model shields the organization from "OPENWAR" and leads to growth and sustainability by meeting the Human Needs via Business Needs as shown in Fig. 1.

The I-TOP model has been introduced in the corporate strategy and business strategy classes for MBA and DBA candidates and has received very positive feedback from the students who are managers and senior managers in their organizations. Some of the students have applied this model in their work and realize it is very effective. With the end in mind of optimization of Return on Investment, this model can be applied as per the requirement of the industry.

\subsection{Technology Infinite Possibilities}

Industry can generally begin with the Technology Infinite Possibilities portion of I-TOP. Organizations must think out of box to move away from competition by injecting novel and noble ideas via of Blue Ocean Strategy, Disruptive Innovation. By doing so, they can focus on optimizing the Return on Investment instead of getting into competitive dynamic world where they always have to spend a lot of time in outdoing their competitors.

Organization can engage in technological innovation possibly motivated by several factors while the aims may include product efficiency, product quality or the ability to adapt to changes. In addressing the challenges of global competition, organization requires the achievement of excellence in innovation to achieve sustainability. Innovation can be a key driver for productivity, increased energy and material efficiency, improve performance of the goods and services as well as in the generation of new markets. 


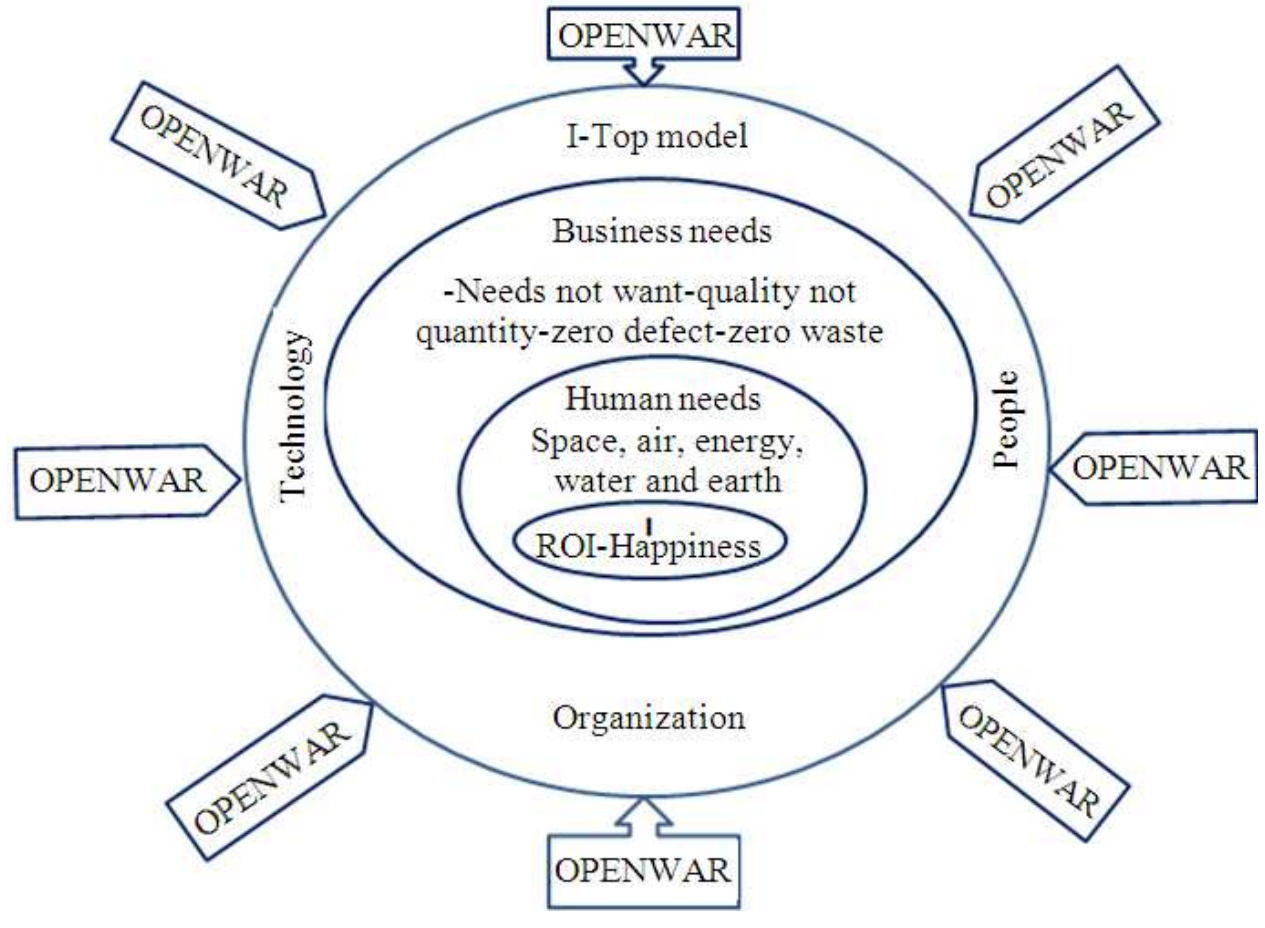

Fig. 1. OPENWAR

The ultimate reason for the technological innovation is to improve the organizational sustainable performance and the organization can gain competitive advantage by introducing new products, which allows the organization to increase market demand. The organization could then increase the demand through product differentiation and not just focusing on a single product by targeting new markets and also by influencing demand for the existing products. Technological innovation involves the utilization of new knowledge with the combination of the existing knowledge. The new knowledge can be generated by the organization through Research and Development (R\&D). Innovation or New Product Development is the fundamental source of value creation in organization which is to identify and develop new products and services and deliver them to market on a timely manner. Li et al. (2007) relates organizational performance in terms of the organization sustainable performance and its financial goals.

Among the factors which influence the organizations innovation performance includes the combination of Research and Development (R\&D) and the product development functions. The increasing speed of innovation requires organizations in almost every industry to innovate as much as possible and to be fast in the innovation process life cycle. Speed in decision making enables organizations to mobilize against new opportunities in order to capture the market first. Murat and Baki (2011) concluded in their studies that firms are more competitive with innovations. Chen and Tsou (2012) suggested that it is in fact better to focus on product innovation and technological advancement for optimum organization performance.

Garcia-Morales et al. (2008) described that firms are better able to get used to market changes and have shorter decision chains and flexibility which leads to organizations success. Study carried out by (Erdil et al., 2004) resulted that organizations innovativeness affects the firm's performance. Prajogo and Ahmed (2006) also commented that there is a positive relationship between innovation and organization performance and that a firm should develop or launch new products to perform better than competitors in respect to organization performance measured. Wolff and Pett (2006) also concluded on the positive effect of product and process innovation as it opens SME's to new customers and markets. He also concluded that product innovation can provide more market share, growth and hence more sales growth.

Hsieh et al. (2008) concluded that marketing and product design should be closely monitored. Yardstick 
on the competitors to manage the conflicts and challenges from the dynamic global market environment are also crucial for an organization. Such activity should develop new products to the market. Many researchers in fact have also ventured to the study and confirmed that the incorporation of product design procedure in an organization improves new product development performance which leads to the organization performance.

Intensity of competition in the market requires organizations to introduce new product introduction to the market in a speedy manner to avoid competitors to lead the market which could incur loss of market share and losing the competition. It is also suggested that organizational innovation facilitates the formation of organizational values and differentiates an organization from its competitors. Without much innovation, industries will be unable to compete successfully in the global market, both in technology driven and traditionally driven as the global market is moving very fast to keep up with the tough competition.

\subsection{Outright Environmental Scanning}

Managers can utilize Outright Environmental Scanning to carry out a proper/elaborate global scenario planning to understand what the possible business opportunities available for novel and noble ideas generated. Upon understanding the possible business opportunities, they could narrow down to probable business opportunities and finally end up with preferred business opportunities. The preferred business opportunities can be determined based on the vision and mission of the organization.

The end results of the global scenario planning will help the organization to form necessary organizational structure and management structure to provide the strategic agility needed to manage the business. The types of organization include local, international, multinational, global and transnational. Depending on the nature of business, the organization can then form the relevant type of organization, for example, for fast cycle products (e.g., semiconductor), transnational organization might be the most suitable. Whereas for slow cycle industry (e.g., cement manufacturer), multinational type of organization might be suitable.

Organization should create excellent and attractive working conditions that inspire the employees today and in the future, therefore the culture it cultivates in the organization is important. Employees' commitment and performance is often infleunced by work environment. There are four types of organization namely Local, International, Multinational and Transnational.
Organizational culture plays an important role in achieving high performance and can be a source of competitive advantage if appropriately nurtured, learnt and shared. The challenge for organization is to create an environment where employees understand and commit to the organizations direction, strategy and goals. Aligning and engaging employees to a clearly expressed strategy require:

- Organization structure where people understand what is expected and what they are accountable for

- Systems and processes that drive the right behaviour

- Leadership capability

- A positive work environment

- Government influence

Employee engagement is related to a range of success factors in business such as employee performance, productivity, safety, attendance and retention. Government could also play their part by assisting the organization in terms of providing incentives, trainings, approving certain loan for starting up a business. It was also concluded that organization culture comprises of exclusive nature of a company. Managers face challenges to look for the culture that probably could enhance the organizational effectiveness because it is strong believed that there are cause and effect associated with each of the dimensions. This implies that with the correct culture, organizational sustainable performance could be achieved.

Cheung et al. (2012) concluded that organization performance is related to organization with strong culture with well integrated set of values, beliefs and the behaviours. That's because focused cultures provide better financial returns, which include higher Return On Investment (ROI), higher Return On Assets (ROA) and higher Return On Equity (ROE). Certain organizational culture leads to superior organizational performance.

Organizational culture and performance exhibit that companies that are able to develop their cultures in a more effective way most probably have the advantage of progression in the productivity and the quality of life of its employees. A study carried out by (Martelli and Abels, 2011) concluded that organizational type does leads to the organizational performance.

\subsection{People-Human Capital Development}

Upon identifying the novel and noble ideas and appropriate organizational structure, most importantly they have to identify the right human resources. People 
in this context refer to the different type of characters and personalities that individual human being possesses.

Employees can be classified into three categories, i.e., Performers, Transactors and Transformers. Performers are employees who are just value for money, in which they just fulfilled duties/roles assigned to them. Transactors are employees who could bring new ideas to value add current process/product offered. Transformers are employees who could bring the organization into blue ocean strategy while applying new ideas.

Kuo (2011) suggests that every person in the job market should be considered a knowledge worker in such a speed emphasized era and that people is considered the most important asset that any company must treasure. Parker et al. (2006) predicted that there is a link between a person's appraisals, emotions and behaviour where appraisal from management towards an employee's work role contributes to motivate the employee to strive for more and eventually contributing to the organization success.

If an organization wants to succeed in the worldwide competition for talent, the company needs the excellent skills of an attractive employer. In addition in providing great career opportunities, flexible hours and multiple methods of communication technology as well as enhancing the creativity concepts which help to implement and support self-determined working condition to the employees. The target is to develop innovative and attractive working conditions in order to support creativity and innovation in the best possible way and thus it will ensure the successful achievement of the organization objective in a dynamic business environment.

Emotions on the other hand refer to ones feeling of joy. Behaviour refers to employee's innovativeness in the job. Shaw et al. (2012) examined the issue of human capital losses and organizational performance and found significant effect.

Tang and Tang (2012) found that human resource management practices affects employees cognition on how they are treated in the organization which then influence the organizational citizenship behaviour. Imenez-Jimenez and Sanz-Valle (2008) stated that individuals if given a chance will demonstrate significant and positive effects on organizational performance. Getting in the correct type of people in an organization is crucial, knowledge sharing among employees is important and healthy for organization success but there are also certain group of people have different thoughts and are also people who is unwilling to share their knowledge with co-workers because they think that knowledge sharing with their co-workers may threaten the knowledge the worker possess within an organization. On the other hand Rosen et al. (2010) examined the role of emotions in intervening the effects of adverse employee outcomes. The paper proposed that employee's frustration lowers the level of performance and increases organizational withdrawal. If there is an employee who is in sync with the organization culture then the employee is more likely to be committed, perform better, stay longer and promote the organization.

Ho (2008) discovers that self development in people is vital in guiding high performance in organization. When these developments in people are carried out, it leads to increase in satisfaction, motivation and performance towards performance growth.

Human possesses skills, experience and knowledge that add economic value to firms or organizations. The human factor is therefore is the fundamental to the achievement to the organization goals. Organization should promote employee to participate in the decision making process which in fact will exhibit the ability of the employees in their initiative to the day to day activities towards organization performance. A study carried out by Sanjeevkumar (2012) examined the relationship between pay, performance and found that when high performers are not rewarded accordingly, they are most likely to leave the organization to work at other place. Hence, this will affect the organizations performance where trained employees will be leaving the organization.

People behave differently in certain specific situation therefore finding the right kind of people for the right kind of job is very crucial. Individual performance of a person is about what a person will do on the assigned task, personal behaviour on the other hand is about how a person solves problems and challenges and has the capability to influence others to follow as well as deals with changes. Personal values are about the rewards required to motivate a person. Personal attributes is about the things which makes a person to focus on and see clearly. Therefore optimizing people is in fact no less important than optimizing any other financial assets.

Social Exchange Theory will also be used to analyse human behaviours which could lead to success or failure of any organization. Social exchange theory suggests that people behave differently and make decisions based on cost and benefits and people make decision based on their individual satisfaction level within an organization. They will evaluate the benefits which they would receive due to their actions especially in an organization. Chiang et al. (2011) did a study on the social exchange theory and argued that employees with 
different identity orientations will in fact generate different social exchange relationships.

Employees' who possesses personal identity orientation focuses on tangible benefits gained from participating in an exchange activity rather than the social rewards. Relational trust strengthens the nature of mutual exchange and promotes employees emotional bonding which in return contributes positively towards organization performance.

\section{CONCLUSION}

The combination above, i.e., Technology Infinite Possibilities, Outright Environmental Scanning and People (Human Capital Development), would enable the organization to optimize their Return on Investment. This paper call upon organizations to formulate their strategy based on this I-TOP model as WIN.

WIN stands for the following acronyms:

- W-Worldwide efficiency

- I-Implementation power

- N-Novel and Noble

Organizations that go through this I-TOP model would be able to form an organization that has worldwide efficiency that is critical for optimizing the ROI, where economic scale of business is one of the important factors. With the appropriate human resource (Transformers), the organization would be able to generate new ideas and implement it timely. The most important is the ideas generated should have the novelty (new) and noble (human and environmental friendly). These factors are important for business ethics and legality that are crucial towards business sustainability. The I-TOP model works well for all organizations in general. For the organizations which fall under slow cycle, the Technology Infinite Possibilities might be of less relevance but the other factors (Outright Environmental Scanning and People (Human Capital Development)) are still of upmost relevance.

To date, this model have been utilised by an MBA graduate to develop a charitable Hospital in Vietnam and a group of DBA students to optimise the ROI in one of the University in Indonesia. Currently, two research projects have been carried out to support the argument discussed in this model. One of the research projects is on the application of the model in mitigating risk among companies in the semiconductor industry. This model is also being used to study the risk agility among the holiday resorts in Penang, Malaysia. Another study was carried out based on this model in the electronics industry while another research project currently applies this model to study the Risk Management Agilities, in which the model is referred to as "R-I-Top Model".

\section{ACKNOWLEDGEMENT}

This research is supported by the Short-term Grant Account No.: 304/PPAMC/6311128, Universiti Sains Malaysia, Penang, Malaysia.

\section{REFERENCES}

Andrey, P. and M. Bourne, 2011. Explaining the effects of performance measurement on performance: An organizational routines perspective. Int. J. Operat. Product. Manage., 31: 101-122. DOI: 10.1108/01443571111098762

Chen, J.S. and H.T. Tsou, 2012. Performance effects of IT capability, service process innovation and the mediating role of customer service. J. Eng. Technol. Manage., 29: 71-94. DOI: 10.1016/j.jengtecman.2011.09.007

Cheung, S.O., P.S.P. Wong and A.L. Lam, 2012. An investigation of the relationship between organizational culture and the performance of construction organizations. J. Bus. Econ., 13: 688704. DOI: $10.3846 / 16111699.2011 .620157$

Chiang, H.H., T.S. Han and J.S. Chuang, 2011. The relationship between high-commitment HRM and knowledge-sharing behavior and its mediators. Int. J. Manpower, 32: 604-622. DOI: 10.1108/01437721111158224

Erdil, S., O. Erdil and H. Keskin, 2004. The relationships between market orientation, firm innovativeness and innovation performance. J. Global Bus. Technol.

Garcia-Morales, V.J., F.J. Llorens-Montes and A.J. Verdu-Jover, 2008. The effects of transformational leadership on organizational performance through knowledge and innovation. Br. J. Manage., 19: 299319. DOI: 10.1111/j.1467-8551.2007.00547.x

Gupta, V., 2008. Cultural basis of high performance organizations. Int. J. Commerce Manage., 21: 221240. DOI: $10.1108 / 10569211111165280$

Ho, L.A., 2008. What affects organizational performance?: The linking of learning and knowledge management. Indus. Manage. Data Syst., 108: 1234-1254. DOI: 10.1108/02635570810914919 
Hsieh, Y.C., H.C. Chiu and Y.C. Hsu, 2008. Supplier market orientation and accommodation of the customer in different relationship phases. Indus. Market. Manage., 37: 380-393. DOI: 10.1016/j.indmarman.2007.02.002

Imenez-Jimenez, D. and R. Sanz-Valle, 2008. Could HRM support organizational innovation? Int. J. Hum. Reso. Manage., 19: 1208-1221. DOI: $10.1080 / 09585190802109952$

Kuo, T.H., 2011. How to improve organizational performance through learning and knowledge. Int. J. Manpower, 32: 581-603. DOI: 10.1108/01437721111158215

Li, Y., Y. Liu and F. Ren, 2007. Product innovation and process innovation in SOEs: Evidence from the Chinese transition. J. Technol. Trans., 32: 63-85. DOI: $10.1007 / \mathrm{s} 10961-006-9009-8$

Martelli, J.T. and P.B. Abels, 2011. Multinational corporations: The changing landscape. Manage. Res. Rev., 34 : 889-909. DOI: $10.1108 / 01409171111152501$

Murat, I.A. and B. Baki, 2011. Antecedents and performance impacts of product versus process innovation: Empirical evidence from SMEs located in Turkish science and technology parks. Eur. J. Innovat. Manage., 14: 172-206. DOI: $10.1108 / 14601061111124885$

Ogbonna, E. and L.C. Harris, 2002. Managing organisational culture. Insights from the hospitality industry. Hum. Reso. Manage. J., 12: 33-53. DOI: 10.1111/j.1748-8583.2002.tb00056.x

Parker, S.K., N. Turner and H.M. Williams, 2006. Modeling the antecedents of proactive behavior at work. J. Applied Psychol., 91: 636-652. DOI: 0.1037/0021-9010.91.3.636
Prajogo, D.I. and P.K. Ahmed, 2006. Relationships between innovation stimulus, innovation capacity and innovation performance. R\&D Manage., 36: 499-515. DOI: 10.1111/j.1467-9310.2006.00450.x

Ramesh, G. and S.R. Devadasan, 2007. Literature review on the agile manufacturing criteria. J. Manuf. Technol. Manage., 18: 182-201. DOI: 10.1108/17410380710722890

Rosen, C.C., C.H. Chang, E. Djurdjevic and E. Eatough, 2010. Occupational Stressors and Job Performance. An Updated Review and Recommendations. In: New Developments in Theoretical and Conceptual Approaches to Job Stress, Perrewe, P.L. and D.C. Ganster (Eds.), Emerald Group Publishing, Bingley, ISBN-10: 1849507120, pp: 1-60.

Sanjeevkumar, D.V., 2012. A study on employee's intention to stay in public companies in Kedah. ZENITH Int. J. Bus. Econ. Manage. Res., 2: 91-101.

Shaw, J.D., T.Y. Park and E. Kim, 2012. A resourcebased perspective on human capital losses, HRM investments and organizational performance. Strategic Manage. J., 34: 572-589. DOI: 10.1002/smj. 2025

Tang, T.W. and Y.Y. Tang, 2012. Promoting serviceoriented organizational citizenship behaviors in hotels: The role of high-performance human resource practices and organizational social climates. Int. J. Hosp. Mgmt., 31: 885-895. DOI: 10.1016/j.ijhm.2011.10.007

Wolff, J.A. and T.L. Pett, 2006. Small-firm performance: modeling the role of product and process improvements. J. Small Bus. Manage., 44: 268-284. DOI: $10.1111 /$ j.1540-627X.2006.00167.x 